\title{
Reduced Tumour Proportion Scores for Programmed Cell Death Ligand 1 in Stored Paraffin Tissue Sections
}

\author{
YUKI SATO $^{1}$, DAICHI FUJIMOTO ${ }^{1}$, KEIICHIRO UEHARA ${ }^{2}$, HAYATO KAWACHI ${ }^{1}$, \\ KAZUMA NAGATA ${ }^{1}$, ATSUSHI NAKAGAWA ${ }^{1}$, KOJIRO OTSUKA ${ }^{1}$, ICHIRO SAKANOUE ${ }^{3}$, \\ HIROSHI HAMAKAWA ${ }^{3}$, YUTAKA TAKAHASHI ${ }^{3}$, YUKIHIRO IMAI ${ }^{2}$ and KEISUKE TOMII ${ }^{1}$ \\ Departments of ${ }^{1}$ Respiratory Medicine, ${ }^{2}$ Clinical Pathology, and ${ }^{3}$ Thoracic Surgery, \\ Kobe City Medical Center General Hospital, Kobe, Japan
}

\begin{abstract}
Background/Aim: We evaluated the effects of storage of formalin-fixed, paraffin-embedded (FFPE) sections on the tumour proportion score (TPS) for programmed cell death ligand 1 (PD-L1), as indicator in non-small cell lung cancer (NSCLC) tissues of treatment efficacy. Materials and Methods: NSCLC postoperative specimens with PD-LI TPS $\geq 50 \%$ were obtained and cut into five serial sections. One section was stained immediately, and four were stored at $4^{\circ} \mathrm{C}$ for 2, 4, 6, or 8 weeks. Slides were subjected to PD-L1 immunohistochemistry using the anti-PD-L1 clone 28-8. PD-L1 TPS were blindly evaluated by two independent pathologists. Results: Twelve specimens (60 slides) were evaluated. After slide storage for 2, 4, 6, and 8 weeks, a TPS of $<50 \%$ was obtained in five (41\%), four (33\%), seven (58\%), and eight (67\%) patients, respectively. Conclusion: TPS values for PD-L1 were reduced by longterm slide storage of FFPE specimens. Sectioned slides should be stained for PD-L1 without delay.
\end{abstract}

Lung cancer is the leading cause of cancer-related deaths worldwide, and non-small cell lung cancer (NSCLC) accounts for approximately $80 \%$ of all lung cancer cases (1). Programmed cell death 1 (PD-1) axis inhibitors have efficacy in patients with advanced NSCLC $(2,3)$. Moreover, previous studies have revealed that the tumour proportion score (TPS) for programmed cell death ligand 1 (PD-L1), i.e. the proportion of positively-stained cells by immunohistochemistry (IHC), is a predictive biomarker for the

Correspondence to: Yuki Sato, MD, Department of Respiratory Medicine, Kobe City Medical Center General Hospital, 2-1-1 Minatojima-Minamimachi, Chuo-ku, Kobe 650-0047, Japan. Tel: +81 783024321, Fax: +81 783027537, e-mail: yuki1130sato@gmail.com

Key Words: Programmed cell death ligand 1, immunohistochemistry, immunotherapy, non-small cell lung cancer. efficacy of PD-1 axis therapies (4, 5). Following the KEYNOTE 024 trial, pembrolizmab (Merck Sharp and Dohme, Kenilworth, NJ, USA) was approved as a first-line therapy for patients who are strongly positive for PD-L1 (TPS $\geq 50 \%$ ) (6).

PD-L1 IHC results determine the treatment strategy for patients with NSCLC. If patients with a true PD-L1 TPS $\geq 50 \%$ are evaluated as having a TPS of less than $50 \%$, they cannot receive immunotherapy as a first-line treatment, yielding a shorter overall survival. Currently, predictive markers other than PD-L1 IHC are not available. Therefore, an accurate evaluation of PD-L1 TPS is necessary.

The accuracy of staining results is limited by technical issues. In fact, the long-term storage of paraffin tissue sections leads to a loss of IHC antigenicity to human epidermal growth factor receptor 2 (HER2), p53, and other antibodies $(7,8)$. According to the guideline on HER2 testing established by the American Society of Clinical Oncology (ASCO)/College of American Pathologists (CAP), specimens should be stained within 6 weeks of sectioning to minimize false-negative results (9). The ATLAS of PD-L1 IHC testing in lung cancer published by the International Association for the Study of Lung Cancer (IASLC) recommends that sectioned slides be stained within 3 months (10). However, to the best of our knowledge, a time-course analysis of PD-L1 IHC results after sectioning has not been performed. The extent of antigenicity loss depends on the type of antigen, and the algorithm for IHC evaluation differs between HER2 and PD-L1. Therefore, it is necessary to investigate the time course of PD-L1 IHC in sectioned slides in order to comprehensively identify candidates for therapy with PD-1 axis inhibitors.

In this study, we investigated the time course of TPS for PD-L1 in NSCLC postoperative paraffin slide sections using clone 28-8 anti-PD-L1 (complementary diagnostics for nivolumab) and proposed optimal pathological processing methods for accurate PD-L1 assessment. 
Table I. Patient characteristics.

\begin{tabular}{lc}
\hline Characteristic & Total $(\%)(\mathrm{N}=12)$ \\
\hline Age (years) & \\
Mean (SD) & $76.5(7.2)$ \\
Gender & $12(100)$ \\
Male & \\
Smoking status & $12(100)$ \\
Current or former & $0(0)$ \\
Never-smoker & \\
Pack-years & $45(33-120)$ \\
Median (IQR) & $2(17)$ \\
Histology & $10(83)$ \\
Adenocarcinoma & \\
Squamous cell carcinoma & $5(42)$ \\
Interstitial pneumonia & \\
Present & $3(25)$ \\
p-Stage & $6(50)$ \\
IA & $2(17)$ \\
IB & $1(8)$ \\
IIA & \\
IIB & $45.0(22.3-91.9)$ \\
Preservation period & \\
Median (IQR), months & $60(50-67.5)$ \\
PD-L1 expression & $8(67)$ \\
Median (IQR), \% & $4(33)$ \\
PD-L1 TPS change after 8 weeks & \\
Impaired to <50\% & \\
Unimpaired &
\end{tabular}

SD: Standard deviation; IQR, interquartile range; pStage: pathological stage; PD-L1: programmed cell death ligand 1.

\section{Materials and Methods}

Patient selection criteria and study design. This study was part of a retrospective study that compared the TPS for PD-L1 of patients with NSCLC with or without interstitial lung disease (ILD) (unpublished data). Patients with pathological stage I or II NSCLC who underwent surgery at Kobe City Medical Center General Hospital (Hyogo, Japan) between January 2007 and January 2016 were reviewed. In total, 826 patients were included in the study, and PD-L1 status was screened in 124 randomly selected patients. Among them, 12 patients had TPS for PD-L1 of at least $50 \%$. The formalin fixation time was 24-72 h. Using FFPE postoperative specimens, five new serial sections were made of each specimen, four of which were stored at $4^{\circ} \mathrm{C}$ for $2,4,6$, or 8 weeks. Patients who reported never having smoked were defined as never smokers, those who had smoked within 1 year of their diagnosis were categorised as current smokers, and the remaining patients were considered former smokers. The FFPE storage period was defined as the period from the day of operation to IHC staining. This study was approved by the Ethics Committee of Kobe City Medical Center General Hospital (zn170303).

Tissue processing and evaluation of IHC. Rabbit monoclonal antiPD-L1 clone 28-8 were used (Abcam, Cambridge, UK). Tissue sections $(4 \mu \mathrm{m}$-thick) were cut from FFPE tumour blocks and then
Table II. Comparison of patient characteristics between impaired and unimpaired tumour proportion score for programmed cell death ligand 1.

\begin{tabular}{lcc}
\hline Characteristic & $\begin{array}{c}\text { Impaired, } \mathrm{n}(\%) \\
(\mathrm{N}=8)\end{array}$ & $\begin{array}{c}\text { Unimpaired, } \mathrm{n}(\%) \\
(\mathrm{N}=4)\end{array}$ \\
\hline $\begin{array}{l}\text { Age (years) } \\
\text { Mean (SD) }\end{array}$ & $76.5(6.1)$ & $76.5(9.9)$ \\
Pack-years & & \\
Median (IQR) & $45(33-66)$ & $52(33-67)$ \\
Histology & & \\
Adenocarcinoma & $1(13)$ & $1(25)$ \\
Squamous cell carcinoma & $7(88)$ & $3(75)$ \\
Interstitial pneumonia & & \\
Present & $3(38)$ & $2(50)$ \\
p-Stage & $3(38)$ & $0(0)$ \\
IA & $2(25)$ & $4(100)$ \\
IB & $2(25)$ & $0(0)$ \\
IIA & $1(13)$ & $0(0)$ \\
IIB & & \\
FFPE storage period & $47.8(24.6-110)$ & $34.8(16.7-48.9)$ \\
Median (IQR), months & & \\
\hline
\end{tabular}

SD: Standard deviation; IQR, interquartile range: FFPE: formalin-fixed, paraffin-embedded; pStage: pathological stage.

routinely deparaffinised and rehydrated $\left(95^{\circ} \mathrm{C}\right.$ for $\left.20 \mathrm{~min}\right)$. The antibody was diluted $1: 500$ and applied according to DAKO (Glostrup, Denmark) recommended detection methods (11-13). Tumour PD-L1 scores were evaluated by two independent pathologists (K.U. and Y.I.). Specimens were considered PD-L1positive when the cell membrane was partially or completely stained, irrespective of staining intensity. Haematoxylin and eosin (HE) staining was used for each case to help orientate the pathologists' reading of the IHC slides. TPS was estimated in increments of $10 \%$. According to previous reports, we set the cutoff value as $50 \%$ (6). Namely, patients with TPS of at least $50 \%$ were considered strongly positive, patients with TPS of $0-49 \%$ were considered weakly positive or negative. Specimens classified as TPS $<50 \%$ were defined as false-negatives. Each slide was anonymised and randomised. Two weeks after the independent examination, PDL1 TPS were confirmed by a central review.

\section{Results}

Patients and specimen characteristics. A total of 12 specimens (60 slides) were included in this study. Patient characteristics are summarised in Table I. All patients were male smokers, and the majority had stage I disease $(n=9$, $75 \%)$ with squamous cell histology $(n=10,83 \%)$. Five patients $(42 \%)$ had ILD, and the median PD-L1 TPS was $60 \%$ [interquartile range (IQR): 50-67.5\%]. The FFPE storage period was 45.0 months (IQR: 22.3-91.9 months).

Relationship between PD-L1 TPS and storage period. Generally, PD-L1 IHC results became less accurate over time. Representative IHC examples are shown in Figure 1. 


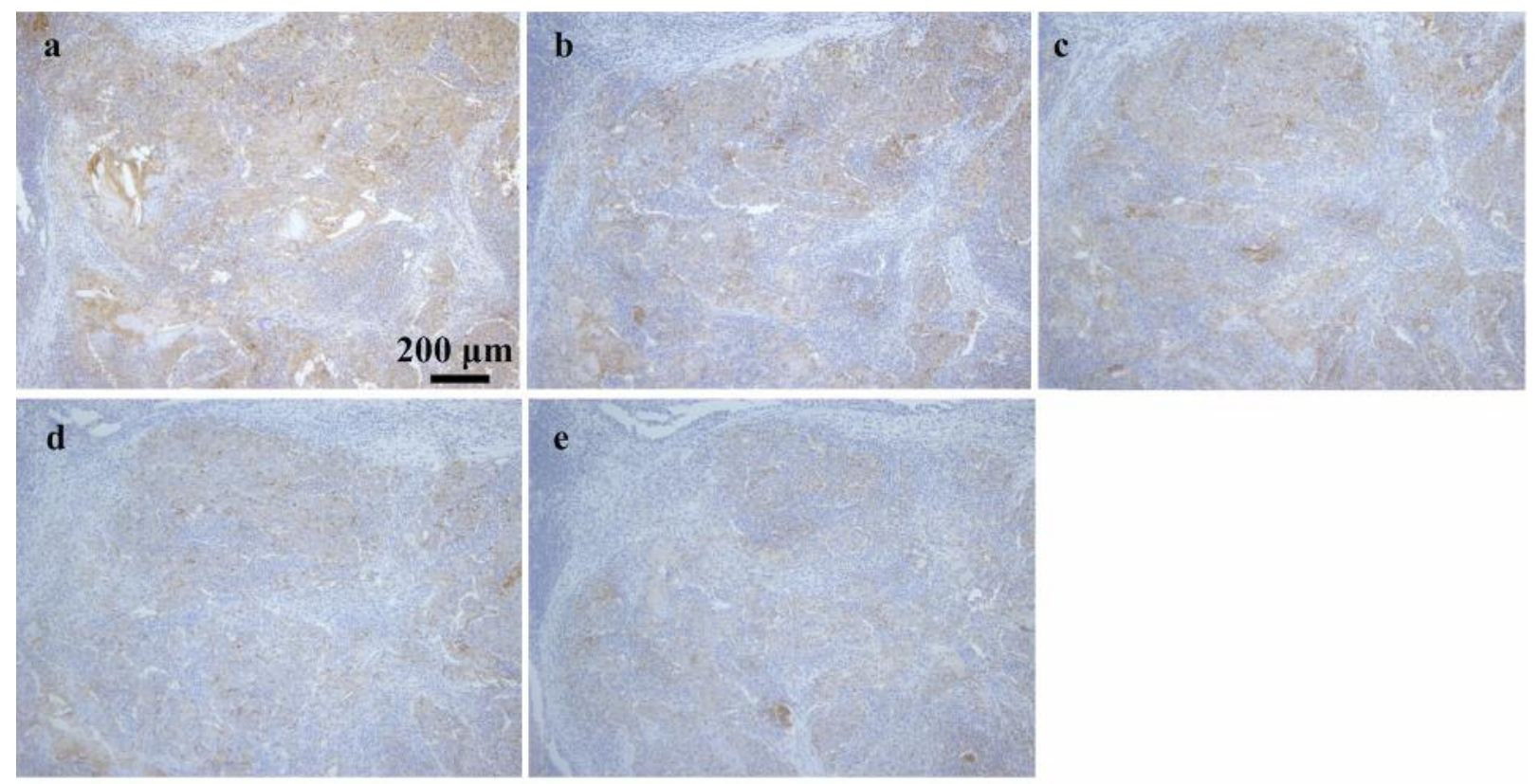

Figure 1. Representative immunohistochemistry results for programmed cell death ligand 1 using clone 28-8 antibodies: a: freshly-stained specimen; $b: 2$ weeks of storage; $c: 4$ weeks of storage; d: 6 weeks of storage; e: 8 weeks of storage $(\times 100)$.

After 2, 4, 6, and 8 weeks storage, specimens of five (41\%), four $(33 \%)$, seven $(58 \%)$, and eight $(67 \%)$ patients were classified as weakly positive (Figure 2).

Differences between patients with impaired and unimpaired TPS. After 8 weeks, the TPS for PD-L1 of eight patients $(67 \%)$ changed from strongly positive to weakly positive. The unchanged group was composed of patients with stage I disease; however, there were no apparent clinical differences in age, smoking status, histology, presence of ILD, stage, and FFPE storage period among patients with impaired and unimpaired TPS (Table II).

\section{Discussion}

To the best of our knowledge, this is the first study demonstrating the time course of PD-L1 TPS after sectioning. Our results revealed that the TPS for PD-L1 decreased substantially over time. A reduction in TPS resulted in an underestimation of the PD-L1 status, yielding false-negative results for patients with initially strongly positive PD-L1 results.

In our study, we found two important features of PD-L1 IHC results according to the time since sectioning. Firstly, there was an apparent impairment, which caused an underestimation of the PD-L1 TPS after long-term storage. Surprisingly, slide storage for 6 weeks or more yielded

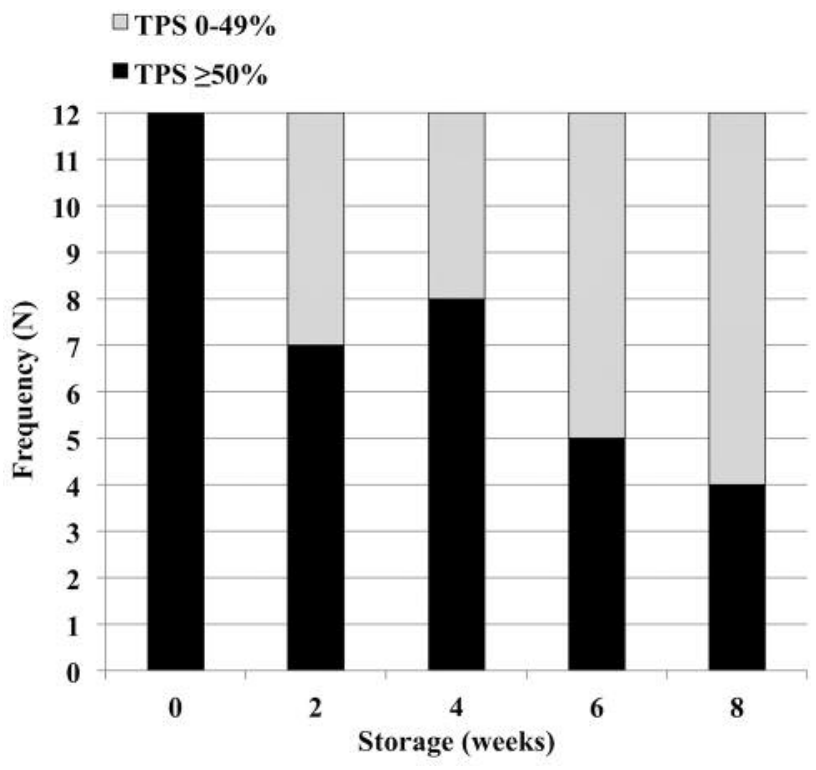

Figure 2. Changes in distribution of the tumour proportion score (TPS) for programmed cell death ligand 1 (PD-L1), using a 50\% cutoff. After 2, 4, 6 , and 8 weeks of slide storage, false-negative results were observed in five (41\%), four (33\%), seven (58\%), and eight (67\%) patients, respectively.

false-negative PD-L1 staining results in more than half of patients with strongly positive PD-L1 on freshly sectioned slides. These results are consistent with those of previous 
reports indicating the impairment of HER2, p53, and Ki-67 IHC staining after long-term slide storage (7, 8, 14-16). Secondly, the observed impairment started 2 weeks after sectioning. Similarly, a previous report demonstrated that p53 staining was impaired after only 2 weeks of storage (7). The PD-L1 TPS determines the patient's prognosis; therefore, we believe that our findings have significant implications for daily clinical practice. Although the ATLAS of PD-L1 IHC testing in lung cancer recommends that sectioned slides be stained within 3 months, clinicians and pathologists should not permit any delay between sectioning and the IHC procedure to ensure the identification of all candidates for therapy with PD-L1 axis inhibitors.

Previous studies have shown that some IHC intensities decrease with long-term slide storage, and a loss of antigenicity of HER2 and p53 has also been reported in tissue microarrays $(7,14-18)$. However, the IHC intensity of oestrogen receptor staining is not affected, and that of vimentin is even elevated by slide storage $(8,15)$. These reports imply that the impairment of antigenicity is not a uniform phenomenon but is specific to each antibody. Oxidation of antigens plays an important role in the loss of antigenicity $(10,19)$. In fact, IHC results are dependent on various conditions, including slide storage duration, storage temperature, FFPE storage period, and antigen retrieval conditions. In this report, we revealed that PD-L1 IHC results become less accurate with storage of slide sections. More studies are needed to optimise the methods for PD-L1 IHC evaluation.

Our study had certain limitations. Firstly, we included only a few specimens collected at a single institution. Secondly, $42 \%$ of patients in this cohort had ILD; therefore, there was patient selection bias. However, a strong tendency for antigenicity loss during slide storage was observed in this analysis. We believe that further largescale studies are warranted to identify all possible candidates for therapy with PD-1 axis inhibitor and to establish optimal pathological processing methods for accurate PD-L1 assessment.

In conclusion, the storage of sectioned NSCLC slides led to the underestimation of PD-L1 TPS. Tissue sections should be stained quickly for evaluation of PD-L1.

\section{Conflicts of Interest}

The Authors have no conflicts of interest to disclose.

\section{Acknowledgements}

This study was supported by internal funding from Kobe City Medical Center General Hospital. The Authors would like to thank Masashi Sugawara, Shuji Imoto and Keiko Sakuragawa for their administrative assistance.

\section{References}

1 Siegel RL, Miller KD and Jemal A: Cancer statistics, 2017. CA Cancer J Clin 67: 7-30, 2017.

2 Borghaei H, Paz-Ares L, Horn L, Spigel DR, Steins M, Ready NE, Chow LQ, Vokes EE, Felip E, Holgado E, Barlesi F, Kohlhaufl M, Arrieta O, Burgio MA, Fayette J, Lena H, Poddubskaya E, Gerber DE, Gettinger SN, Rudin CM, Rizvi N, Crino L, Blumenschein GR Jr., Antonia SJ, Dorange C, Harbison CT, Graf Finckenstein F and Brahmer JR: Nivolumab versus docetaxel in advanced nonsquamous non-small-cell lung cancer. N Engl J Med 373: 1627-1639, 2015.

3 Brahmer J, Reckamp KL, Baas P, Crino L, Eberhardt WE, Poddubskaya E, Antonia S, Pluzanski A, Vokes EE, Holgado E, Waterhouse D, Ready N, Gainor J, Aren Frontera O, Havel L, Steins M, Garassino MC, Aerts JG, Domine M, Paz-Ares L, Reck M, Baudelet C, Harbison CT, Lestini B and Spigel DR: Nivolumab versus docetaxel in advanced squamous-cell nonsmall-cell lung cancer. N Engl J Med 373: 123-135, 2015.

4 Carbognin L, Pilotto S, Milella M, Vaccaro V, Brunelli M, Calio A, Cuppone F, Sperduti I, Giannarelli D, Chilosi M, Bronte V, Scarpa A, Bria E and Tortora G: Differential activity of nivolumab, pembrolizumab and MPDL3280A according to the tumor expression of programmed death-ligand-1 (PD-L1): sensitivity analysis of trials in melanoma, lung and genitourinary cancers. PLoS One 10: e0130142, 2015.

5 Abdel-Rahman O: Correlation between PD-L1 expression and outcome of NSCLC patients treated with anti-PD-1/PD-L1 agents: A meta-analysis. Crit Rev Oncol Hematol 101: 75-85, 2016.

6 Reck M, Rodriguez-Abreu D, Robinson AG, Hui R, Csoszi T, Fulop A, Gottfried M, Peled N, Tafreshi A, Cuffe S, O'Brien M, Rao S, Hotta K, Leiby MA, Lubiniecki GM, Shentu Y, Rangwala R, Brahmer JR and KEYNOTE-024 Investigators: Pembrolizumab versus chemotherapy for PD-L1-positive nonsmall-cell lung Cancer. N Engl J Med 375: 1823-1833, 2016.

7 Jacobs TW, Prioleau JE, Stillman IE and Schnitt SJ: Loss of tumor marker-immunostaining intensity on stored paraffin slides of breast cancer. J Natl Cancer Inst 88: 1054-1059, 1996.

8 van den Broek LJ and van de Vijver MJ: Assessment of problems in diagnostic and research immunohistochemistry associated with epitope instability in stored paraffin sections. Appl Immunohistochem Mol Morphol 8: 316-321, 2000.

9 Wolff AC, Hammond ME, Hicks DG, Dowsett M, McShane LM, Allison KH, Allred DC, Bartlett JM, Bilous M, Fitzgibbons P, Hanna W, Jenkins RB, Mangu PB, Paik S, Perez EA, Press MF, Spears PA, Vance GH, Viale G, Hayes DF, American Society of Clinical $\mathrm{O}$ and College of American Pathologists: Recommendations for human epidermal growth factor receptor 2 testing in breast cancer: American Society of Clinical Oncology/College of American Pathologists clinical practice guideline update. J Clin Oncol 31: 3997-4013, 2013.

10 Tsao MS, Kerr KM, Dacic S, Yatabe Y and Hirsch FR: IASLC atlas of PD-L1 immunohistochemistry testing in lung cancer. An IASLC publication published by Editorial Rx Press 2017. https://www.iaslc.org/sites/default/files/wysiwyg-assets/pd11_atlas_book_lo-res.pdf

11 Gaule P, Smithy JW, Toki M, Rehman J, Patell-Socha F, Cougot D, Collin P, Morrill P, Neumeister V and Rimm DL: A quantitative comparison of antibodies to programmed cell death 1 ligand 1. JAMA Oncol 3: 256-259, 2016. 
12 Phillips T, Simmons P, Inzunza HD, Cogswell J, Novotny J Jr., Taylor $\mathrm{C}$ and Zhang X: Development of an automated PD-L1 immunohistochemistry (IHC) assay for non-small cell lung cancer. Appl Immunohistochem Mol Morphol 23: 541-549, 2015.

13 Neuman T, London M, Kania-Almog J, Litvin A, Zohar Y, Fridel L, Sandbank J, Barshak I and Vainer GW: A harmonization study for the use of 22C3 PD-L1 immunohistochemical staining on Ventana's platform. J Thorac Oncol 11: 1863-1868, 2016.

14 Shin HJ, Kalapurakal SK, Lee JJ, Ro JY, Hong WK and Lee JS: Comparison of p53 immunoreactivity in fresh-cut versus stored slides with and without microwave heating. Mod Pathol 10: 224230, 1997.

15 Bertheau P, Cazals-Hatem D, Meignin V, de Roquancourt A, Verola O, Lesourd A, Sene C, Brocheriou C and Janin A: Variability of immunohistochemical reactivity on stored paraffin slides. J Clin Pathol 51: 370-374, 1998.

16 Wester K, Wahlund E, Sundstrom C, Ranefall P, Bengtsson E, Russell PJ, Ow KT, Malmstrom PU and Busch C: Paraffin section storage and immunohistochemistry. Effects of time, temperature, fixation and retrieval protocol with emphasis on p53 protein and MIB1 antigen. Appl Immunohistochem Mol Morphol 8: 61-70, 2000.
17 DiVito KA, Charette LA, Rimm DL and Camp RL: Long-term preservation of antigenicity on tissue microarrays. Lab Invest 84 : 1071-1078, 2004.

18 Fergenbaum JH, Garcia-Closas M, Hewitt SM, Lissowska J, Sakoda LC and Sherman ME: Loss of antigenicity in stored sections of breast cancer tissue microarrays. Cancer Epidemiol Biomarkers Prev 13: 667-672, 2004.

19 Blind C, Koepenik A, Pacyna-Gengelbach M, Fernahl G, Deutschmann N, Dietel M, Krenn V and Petersen I: Antigenicity testing by immunohistochemistry after tissue oxidation. J Clin Pathol 61: 79-83, 2008.
Received December 7, 2017

Revised January 15, 2018

Accepted January 16, 2018 